\title{
Seismic Microzonation of Mandalay City, Myanmar
}

\author{
Pyi Soe Thein ${ }^{1,2}$, Junji Kiyono ${ }^{1}$, Tun Tun $\mathrm{Win}^{2}$, Than Than $\mathrm{Nu}^{2}$ and Day Wa Aung ${ }^{3}$ \\ 1. Graduate School of Global Environmental Studies, Kyoto University, Kyoto 615-8540, Japan \\ 2. Department of Geology, University of Mandalay, Mandalay 05032, Myanmar \\ 3. Department of Geology, University of Yangon, Yangon 11041, Myanmar
}

\begin{abstract}
Understanding the parameters of PGA (peak ground acceleration) is very important for seismic hazard mitigation and environmental planning in Mandalay City, Myanmar. In this study, fifty SPTs (Standard Penetration Tests) measurement data were collected in Mandalay City, for calculating average shear velocity $\mathrm{Vs}_{30}$, which will be used in seismic microzonation mapping. The shear wave velocity $\mathrm{Vs}_{30}$ of the top layer is $\mathrm{Vs}_{30} \leq 220 \mathrm{~m} / \mathrm{s}$. The ground motion characteristic was estimated by means of the predominant periods and linear magnification factors obtained using the multiple reflection analysis. The highest potential zone of seismic hazard mostly locates the north western marginal part of Mandalay city, in the proximal portion to the dextral Sagaing fault.
\end{abstract}

Key words: SPTs, shear wave velocity $\mathrm{Vs}_{30}$, multiple reflection analysis, Sagaing fault.

\section{Introduction}

Mandalay City is the famous cultural center of Myanmar and the population is about one million. There are also greater population, higher urbanization, more industrialization and many infrastructures. Actually, the city is located very closed to the most active dextral Sagaing fault in Myanmar. In the historical record, several earthquakes happened in and around Mandalay, Amarapura, Innwa, Sagaing region from the beginning of the year of 1400. Even a moderately strong earthquake may cause great loss of lives and property damage. This research will solve part of this problem especially for Mandalay City. In this research, the development of a high resolution near-surface Mandalay City $\mathrm{Vs}_{30}$ model is presented, including descriptions of the processing steps applied to the SPT (standard penetration test) dataset, the consideration made for the seismic microzonation mapping of the selected spatial interpolation schemes. This $\mathrm{Vs}_{30}$ model provides a characterization of the near-surface shear wave velocity of the Mandalay City that has useful connotations for site classification. The

Corresponding author: Pyi Soe Thein, Dr., research field: engineering geology. E-mail: pyisoethein@yahoo.com; pyisoethein.22a@st.kyoto-u.ac.jp. seismic microzonation maps are developed by using the multiple reflection analysis.

\section{Regional Geology and Tectonic Setting}

Tectonically, Myanmar is located in the eastern part of the Cenozoic Alpine-Himalayan Orogenic Belt or the active Alpide Seismic Belt, which extends from the Mediterranean region eastward through Middle East and Himalayan Arc (Fig. 1). At the eastern end of Himalayan Syntaxis, the belt turned sharply to south-southeasterly direction through Myanmar, Andaman-Nicobar islands, Sumatra and other Indonesian islands to the southeast. Plate collision, active subduction, active volcanism and active strike-slip movement are currently in progress along the eastern part, from the Himalayan Arc eastward of this seismotectonic belt, the southern boundary of which is the locus of plate convergence between the India/Australia Plate and the Eurasian Plate. The Indian Ocean floor is subducting eastward in the Indonesian region, with the obliquity of suduction increasing northward along the convergent zone through offshore west of the Andaman Islands to the west coast of Myanmar, and extends further on land to the East Himalayan Syntaxis, generating earthquakes. 


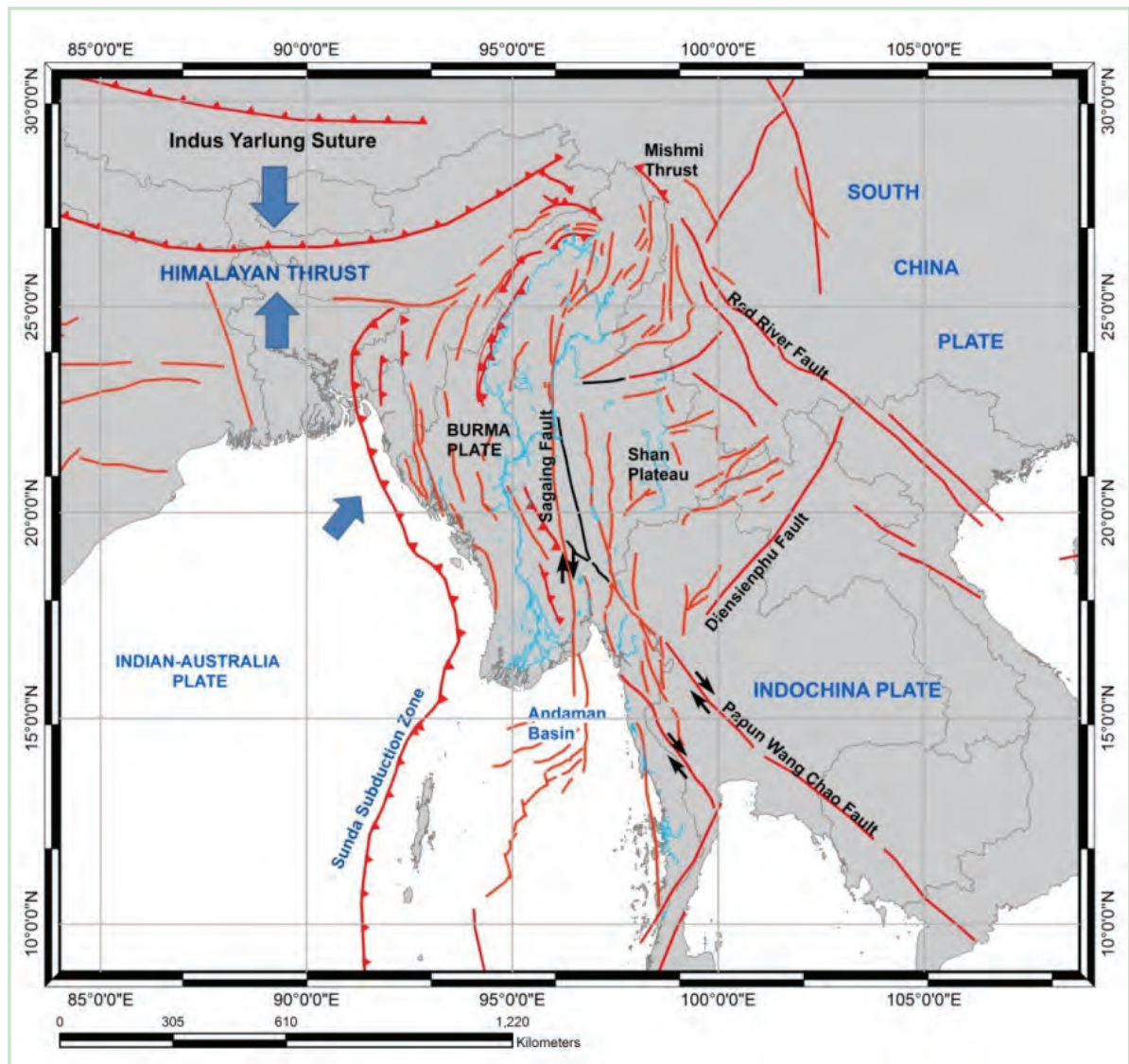

Fig. 1 Tectonic map of Myanmar [11].

Mandalay City covers the central part of Myanmar, approximately from latitude $21^{\circ} 51^{\prime}$ to $22^{\circ} 1^{\prime} \mathrm{N}$ and longitude $96^{\circ} 3^{\prime}$ to $96^{\circ} 8^{\prime} \mathrm{E}$. It includes the major part of the boundary between Sagaing fault in the west $(8 \mathrm{~km}$ from Mandalay), Shan scarp fault and Kyaukkyan fault in the east, Shweli and Moemeik faults in the north. The Sagaing fault is a major strike-slip right-lateral continental fault that extends over $1,200 \mathrm{~km}$ and connects to the Andaman spreading center at its southern termination (Fig. 2). This fault was noticed early by Refs. [1-3] and later confirmed by several authors [4-9]. Moreover, some active faults also occurred in Myanmar, e.g. Sagaing dextral fault, Kyaukkyan fault, Kyaukme fault, Momeik fault, Shan scarp fault, Kabaw fault, Nama fault and Gwegyo fault, etc. Among them, Sagaing is the most active fault and several high magnitude earthquakes have been originated from this fault.

\section{Seismological Setting}

The seismicity of the Myanmar is associated with the activity along the Alpide Seismic Belt, which is one of the most active seismogenic regions in the world. The largest historic event in the Mandalay area i.e. March 23, 1839 Innwa earthquake and July 16, 1956 Sagaing earthquake must have originated from huge sagaing strike-slip fault. Innwa earthquake affected cities comprise Innwa, Amarapura and Mandalay. The total death tolls are about three to four hundred in Innwa and Mandalay and the earthquake magnitude was also estimated as Mercalli scale IX. In the banks of Ayeyarwady River between Amarapura and Innwa and in Mandalay, several chasms of from five to twenty feet in width were resulted, from which large quantities of water and sand were ejected, representing the liquefaction characteristics [10]. Sagaing earthquake caused 40 to 50 death tolls and several buildings including pagodas 


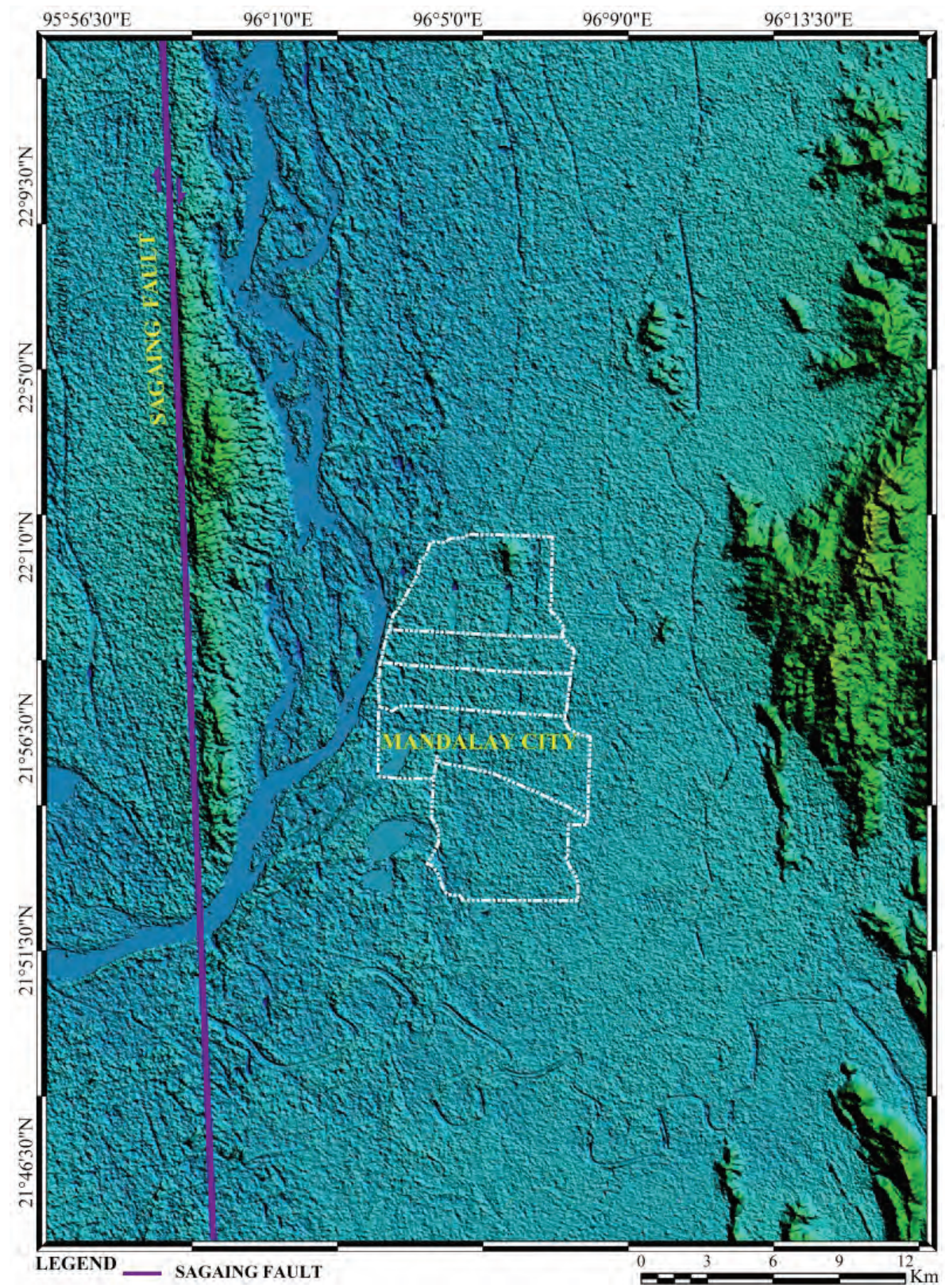

Fig. 2 Tectonic features of Sagaing Fault.

were destroyed [10]. The Sagiang bridge was displaced for a few feet. The damage properties in Mandalay were as not high as in Sagaing [11]. The evidences of the earthquake that damaged in the past are well demonstrated or observed through the tectonic features such as fault, shear zones, fault scraps, or from historical documented records of eye witness accounts, etc. There are many historical and recent earthquakes that are well-known, not only for its magnitude but also for the casualties it brought forth. The historical and recent earthquakes data show that Mandalay City is very vulnerable to earthquake disasters. The epicenter distribution of Mandalay City and its vicinity for the years 1968-2017 are compiled from USGS website [12] (Figs. 3a and 3b). The projections in this figure are based on digital elevation model from SRTM satellite image in 30-meter resolution. The variation in sizes of the circle suggests relative magnitude. Shallow seismicity characterizes along the Sagaing strike-slip fault zone, whereas the India-Eurasia subduction system 


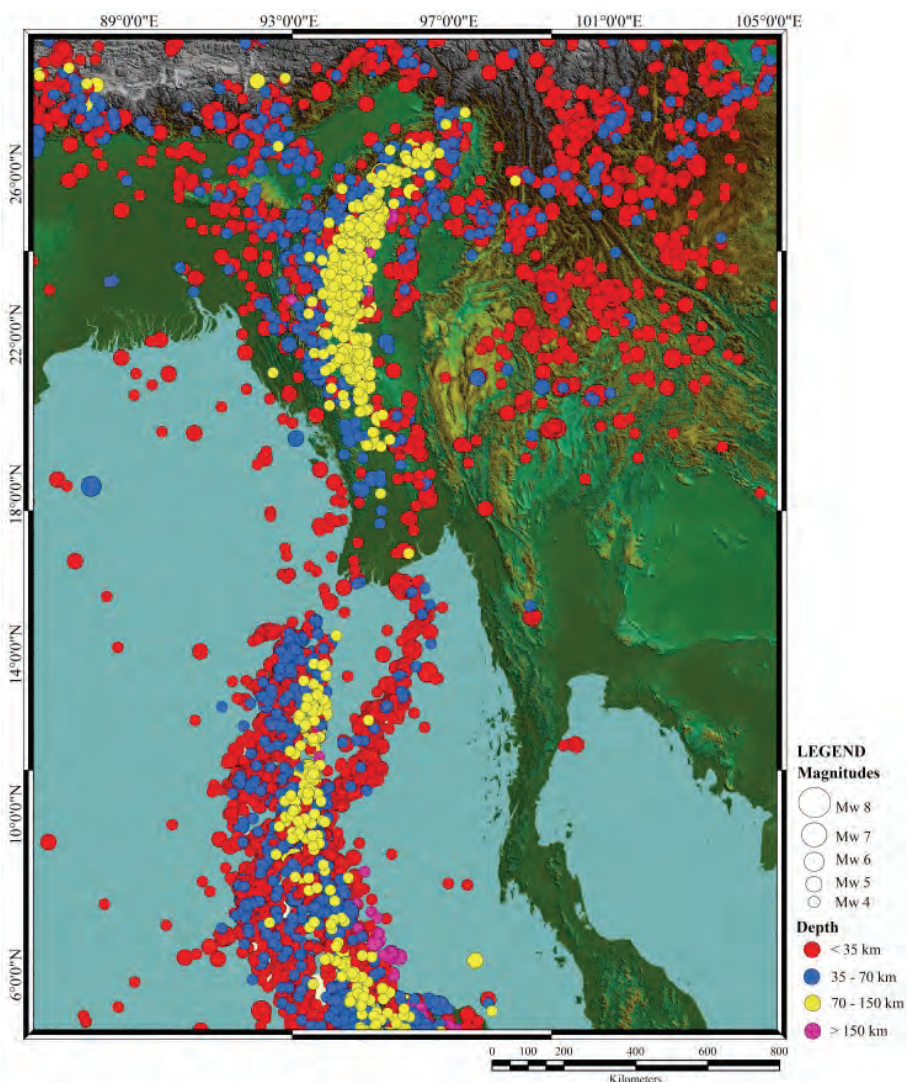

(a) Myanmar and surrounding area

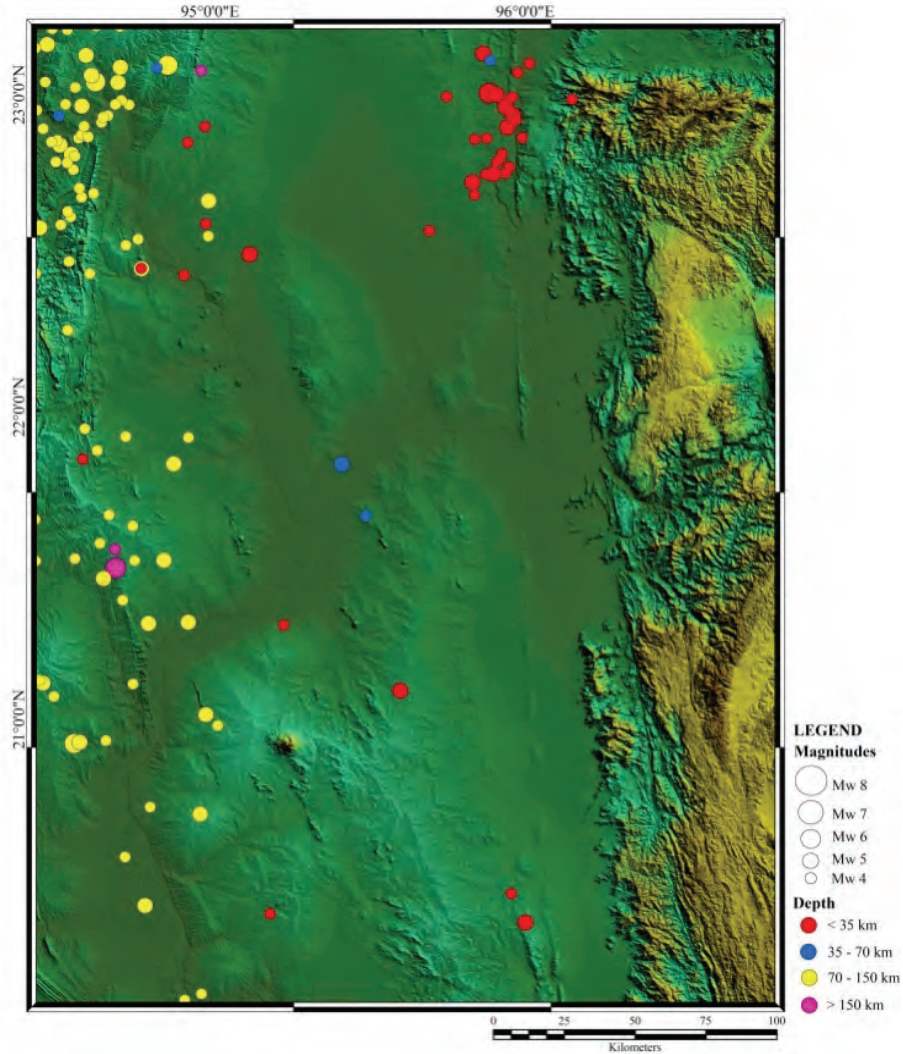

(b) Near Mandalay Region

Fig. 3 Seismicity map showing the distribution of the epicenters of the significant recorded earthquake [12]. 
in the west and Sunda subduction system in the South of Myanmar exhibit high and intermediate-depth seismicity.

\section{SPT Dataset and $\mathrm{Vs}_{30}$ Model}

Fifty borehole data were collected to evaluate the subsurface profiles and related geotechnical parameters for seismic microzonation analyses. The detailed drilling program had been carried out for subsurface investigation in Mandalay City. Fifty boreholes were generally drilled up to $30 \mathrm{~m}$ (Fig. 4). Due to the limitation of the boring depth, we assumed that below the bottom layer (mostly $30 \mathrm{~m}$ ) is the engineering bedrock and its shear wave velocity is $400 \mathrm{~m} / \mathrm{s}$.

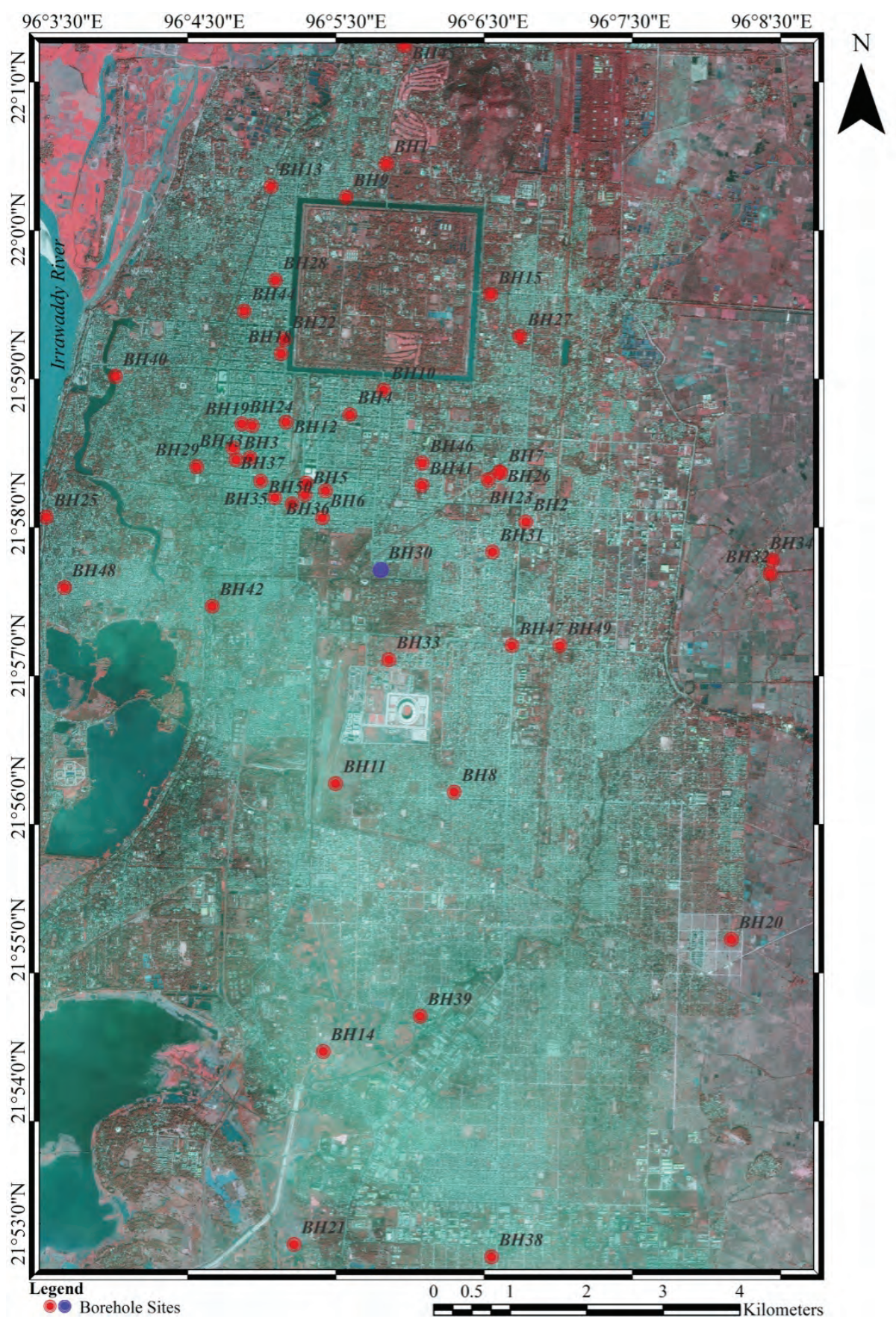

Fig. 4 Satellite image of Mandalay City with 50 borehole sites. 
The SPT dataset is used to develop surfaces describing the distribution of time-averaged shear wave velocity, $\mathrm{Vs}_{30}$, across the urban area in Mandalay. Target profile depths of $5,10,20,30 \mathrm{~m}$ were considered to allow for an assessment of the distributions of soil stiffness with depth across the region. $\mathrm{Vs}_{30}$ values are computed for each target depth, as Eq. (1) [13]. The evaluated subsurface profiles for each area in Mandalay City are shown in the following Fig. 5.

$$
\mathrm{Vs}_{30}=\frac{\sum d_{i}}{\sum t_{i}}=\frac{\sum d_{i}}{\sum\left(\frac{d_{i}}{v s_{i}}\right)}
$$

where $v_{s i}$ is shear wave velocity, $d_{i}$ thickness of $i$ layer and $t_{i}$ one way traveltime in $i_{\text {th }}$ layer.

\section{Predominant Periods}

The MRA (Multiple Reflection Analysis) was used to calculate the transfer function, which expresses the relation between the period and the corresponding magnification factor. Calculation of predominant period by using boring data and the ground model profile is done according to the MRA. The governing equation is

$$
\rho \frac{\delta^{2} \mu}{\delta t^{2}}=G \frac{\delta^{2} \mu}{\delta Z^{2}}+\eta \frac{\delta^{3} \mu}{\delta Z^{2} \delta t}
$$

in which $\mu$ is the displacement of horizontal S-wave (SH), Z the direction of wave propagation (up-down), $t$ the time, $\rho$ the density, $G$ the shear modulus and $\eta$ the coefficient of visco-elasticity. The soil damping is considered by giving the complex value to the shear modulus and solving Eq. (2). The damping constant is $5 \%$ of critical damping for each layer.

The H/V spectral ratio of microtremor observation is frequently used for estimating predominant period of the surface ground. We here estimate the predominant period by calculating transfer function of model ground based on the SPT data. The multiple reflection analysis is the linear analysis, however, above $\mathrm{H} / \mathrm{V}$ ratio results also obtained as linear vibration phenomena. Therefore we adopted this method for the determination of ground motion parameter. Fig. 6 shows examples of transfer functions.

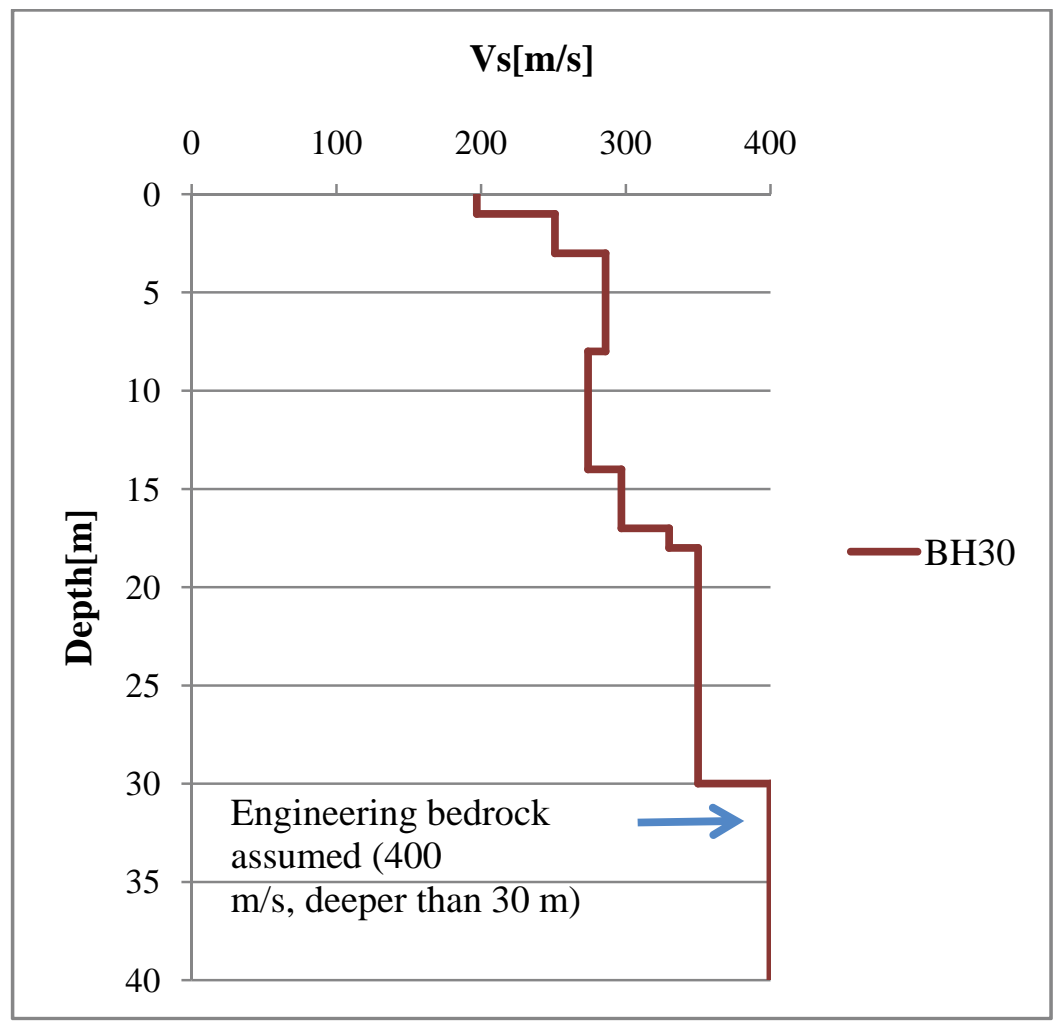

Fig. 5 Example of Vs profile at Mahaaungmye Township, Mandalay City (Blue color in Fig. 4). 
Distinct peaks express the characteristics of the layers for which the shear wave velocity is quite different. The shorter and longer periods are corresponding to a shallow and a deep soil layer or hard and soft soil. Fig. 6 reflects an effect of different soil characteristics, respectively. Although the predominant period does not always indicate the characteristics of an individual layer because typically the actual shaking mode of the ground is complex, it was assumed that the long and short periods reflected information from each layer. Although there are 50 observation points, the points are not adequate to cover all the target area. If each value of the predominant period obtained is considered to be a realization of a stochastic random field. Space interpolation is conducted by ordinary Kriging technique [14-16].

The predominant period of a site is a key parameter which is frequently utilized in site specific earthquake risk analyses. In the frame work of microzonation studies the value of predominant period can be estimated either experimentally or computationally (analytically or numerically) by utilizing measured $\mathrm{Vs}_{30}$ profiles. According to Fig. 7, a limited area at the northern side of the city has lower values of periods

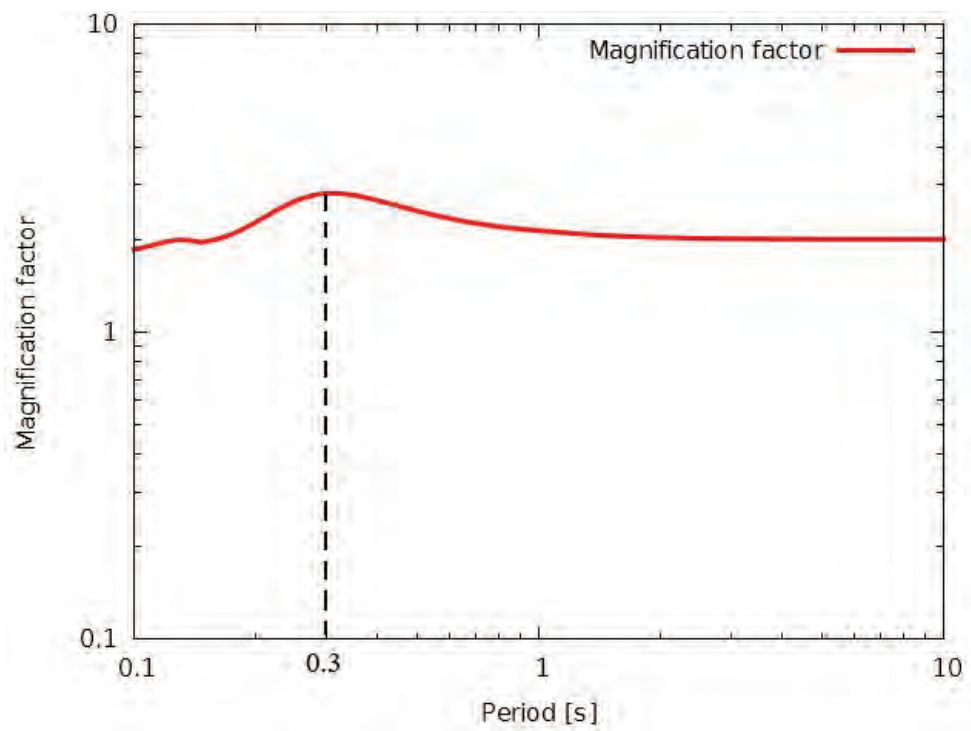

(a) Predominant period appears in a shorter period

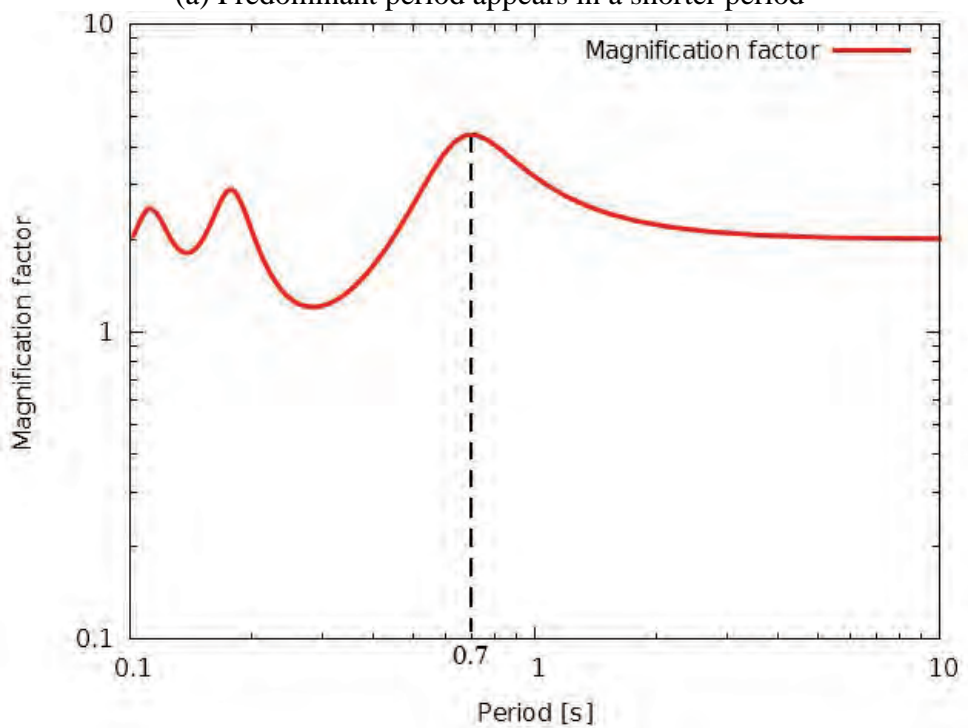

(b) Predominant period appears in a longer period

Fig. 6 Example of the predominant periods. 


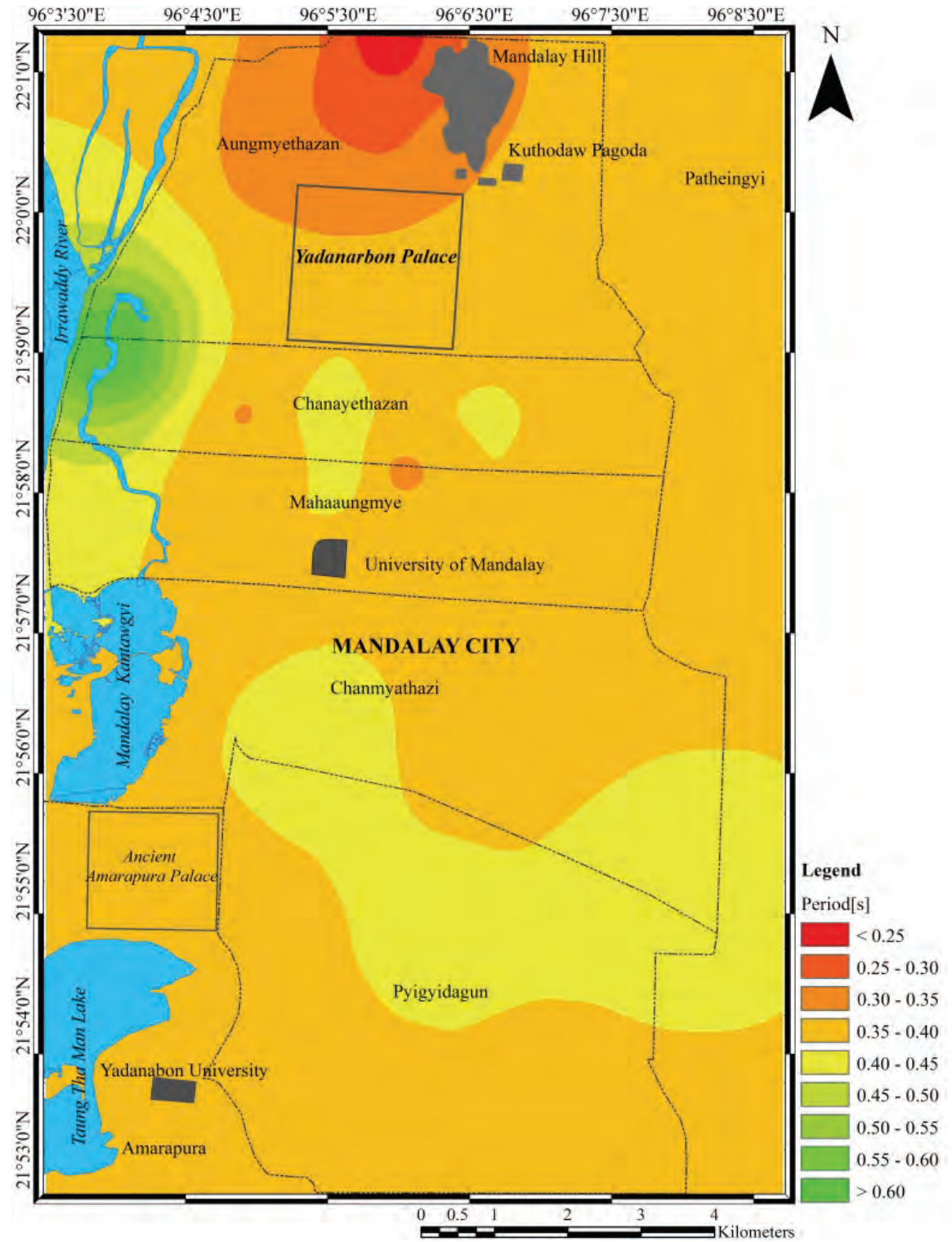

Fig. 7 Predominant periods in Mandalay City $\mathrm{Vs}_{30}$.

( $<0.25 \mathrm{~s}$ ) indicating the presence of subsoil conditions compared to the other parts of the Mandalay City. The lower predominant periods can be observed in the northern portion of the city with the range of 0.25-0.35 [s], and this portion includes the downtown part of Aungmyethazan township and the northern most part of Yadanarbon Palace. The predominant higher periods range belongs to the South-Western parts of Yadanarbon palace and is close to the Irrawaddy river. The predominant periods value is $0.35-0.45$ [s]. This portion includes Aungmyethazan, Chanayethazan and Mahaaungmye, Amarapura, Pyigyidagun and
Patheingyi township.

The weighted average value of shear wave velocity, $\mathrm{Vs}$, in the upper $30 \mathrm{~m}$ of ground is denoted as $\mathrm{Vs}_{30}$ and is being used extensively worldwide to characterize a site in terms of the expected characteristics of earthquake shaking, despite the criticism expressed by several investigators. Based on the existing borehole data and the shear wave velocity data, the $\mathrm{Vs}_{30}$ map is developed for this city. The spatial variation of $\mathrm{Vs}_{30}$ in the urban area of Mandalay is shown in Fig. 8. With regards to the $\mathrm{Vs}_{30}$, nearly all of the sites comprise the $\mathrm{Vs}_{30}$ range of $220-340 \mathrm{~m} / \mathrm{s}$, the lateral changes of the 


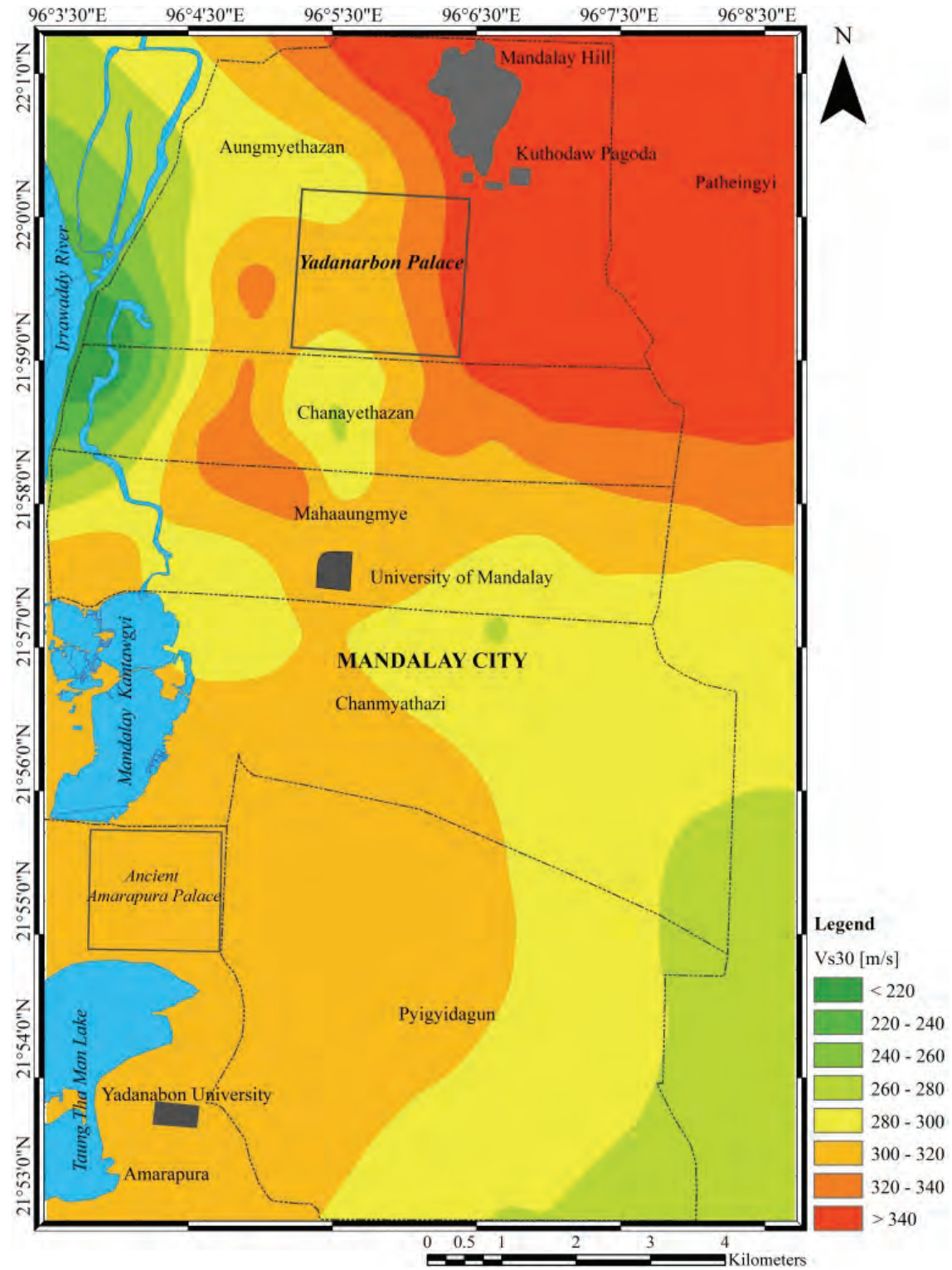

Fig. 8 Spatial variation of $\mathrm{Vs}_{30}$ in the Mandalay City.

soil properties, in terms of $\mathrm{Vs}_{30}$ values are in East-West direction. The minimum $\mathrm{Vs}_{30}$ range, $220-320 \mathrm{~m} / \mathrm{s}$, constitutes in the western part of the city, comprising Aungmyethazan, Chanayethazan, Mahaaungmye, Chanmyathazi, Pyigyidagun and Amarapura townships. The maximum $\mathrm{Vs}_{30}$ values can be observed in the northeastern part of the city, with the range of 320-340 $\mathrm{m} / \mathrm{s}$ in Patheingyi township.

\section{The Previous Probabilistic Seismic Hazard Model of Myanmar}

Seismic microzonation studies are generally considered as a prerequisite for the site specific risk analysis to mitigate earthquake losses or damages. The first relevant applications appeared in Myanmar at recent years [17-19]. Myo Thant et al. [20] have recently demonstrated the reliability of a carefully planned microzonation study in Myanmar by comparing the areal seismic sources for the subduction zone of Indian-Australia Plate beneath Eurasia Plate, in the west of country and for the collision zone of Indian-Australia Plate and Eurasia Plate, in the north-west are re-identified and re-characterised in new model (Fig. 9). 


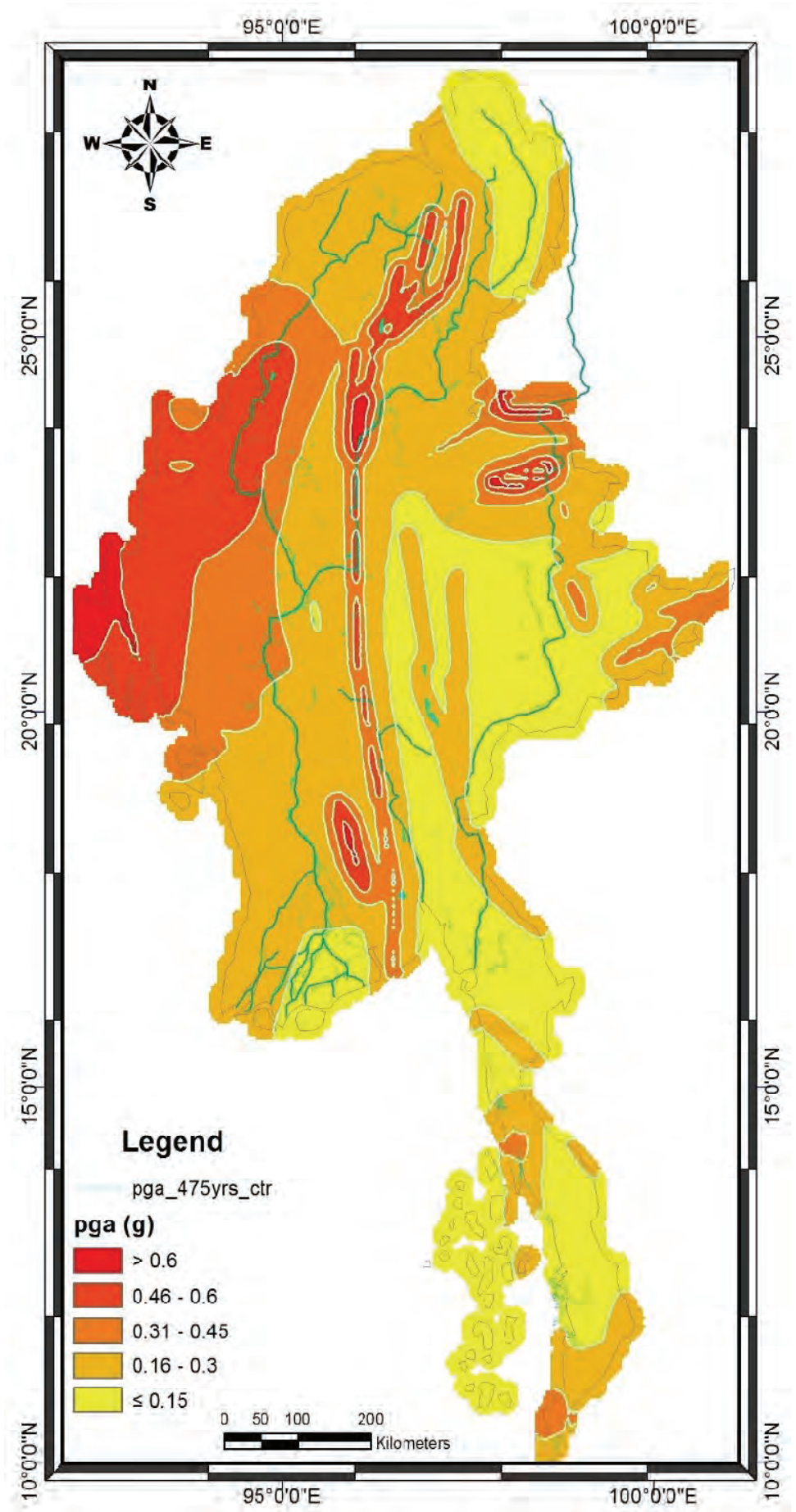

Fig. 9 Probabilistic Peak Ground Acceleration Map of Myanmar for $10 \%$ probability of exceedance in 50 years for engineering bedrock condition [20].

\section{PGA (Peak Ground Acceleration)}

The PGA map in the city of Mandalay was estimated by performing seismic response analyses at all sites of SPT measurements. In the seismic microzonation study, the input motions were selected based on the Probabilistic PGA (Peak Ground Acceleration) (g) Map of Myanmar for 10\% probability of exceedance in 50 years, for engineering bedrock condition (Fig. 9). The ground response analyses were conducted by using 
the assumption of vertical propagation of shear waves from the engineering bedrock to the ground surface. The peak horizontal ground acceleration of these seismic events ranged from $0.35 \mathrm{~g}$ to $0.65 \mathrm{~g}$ with corresponding of magnification ranging from 2.2 to 3.8 (Fig. 10). The estimated PGA results are illustrated in Fig. 11. The highest seismic hazard zones mostly constitute the north western marginal part of Mandalay city, located in the proximal portion to the Sagaing fault. In both cases, the highest seismic zone comprises the western part of Aungmyethazan, Chanayethazan and Mahaaungmye township, and the second-most highest zone consists of Amarapura, Chanayethazan, Mahaaungmye, Chanmyathazi and Pyigyidagun townships and the eastern-most part of Patheingyi township.

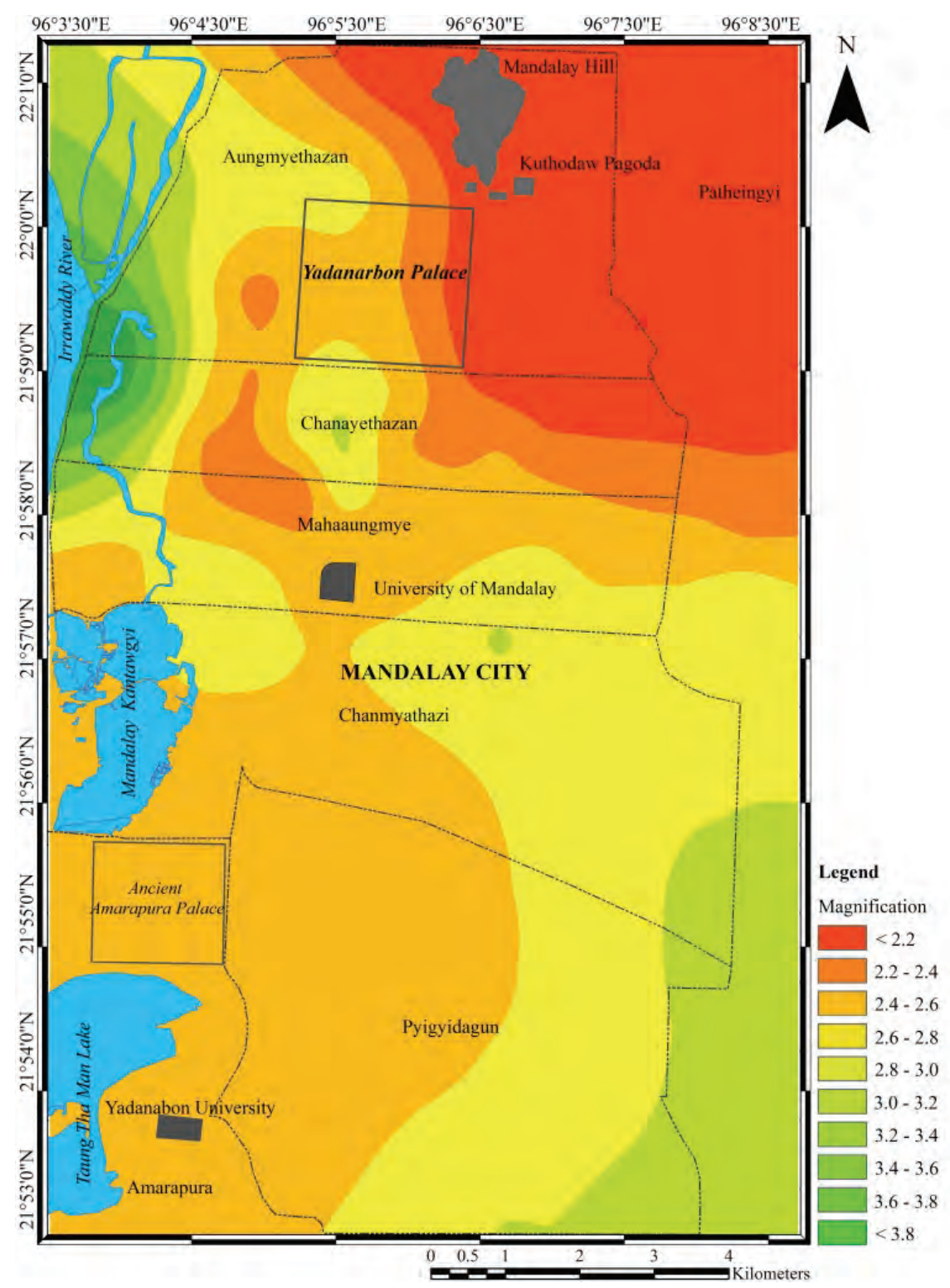

Fig. 10 Magnification map of Mandalay City. 


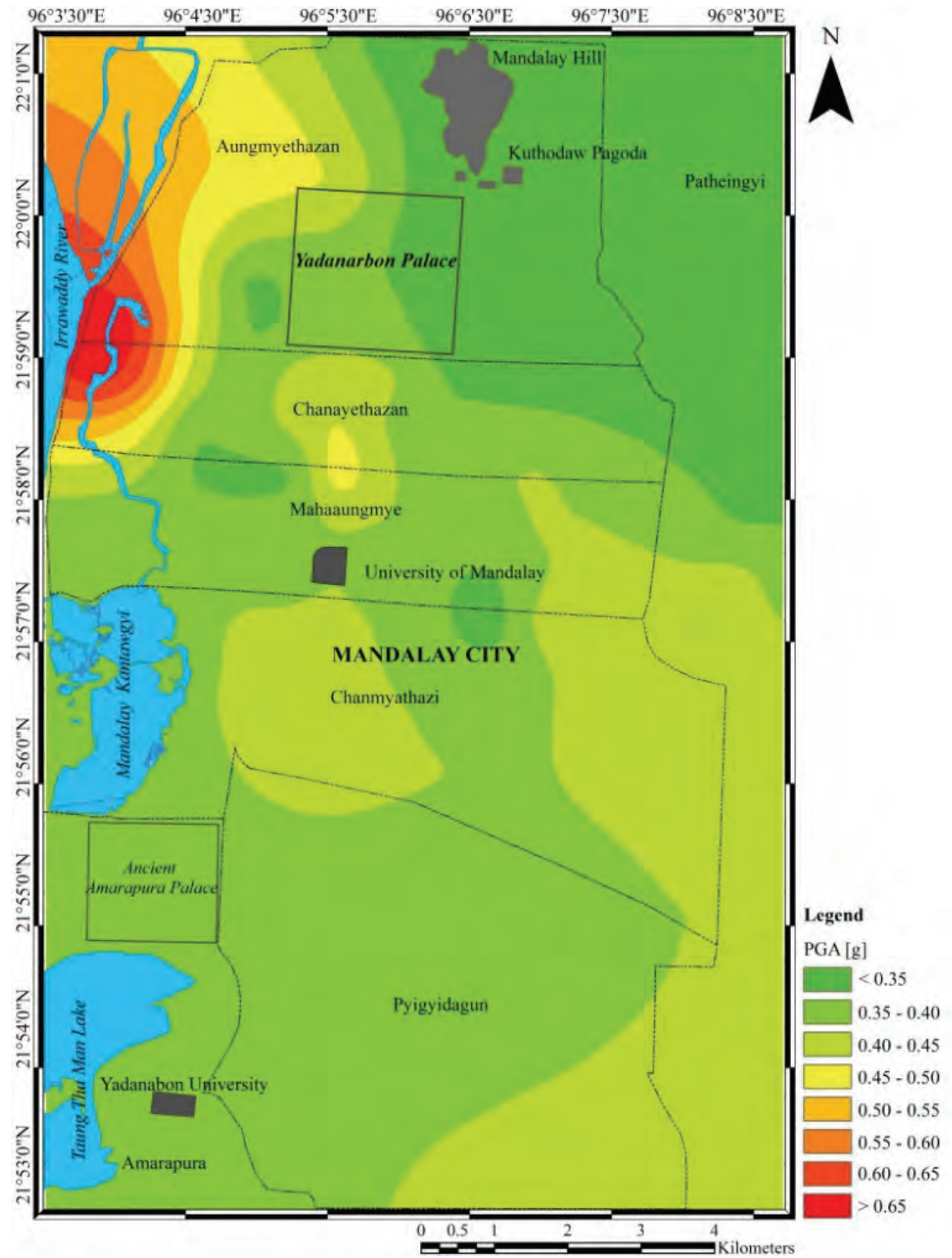

Fig. 11 Estimated PGA map of Mandalay City.

\section{Conclusions}

This research mainly focuses on the results of seismic microzonation based on collected fifty SPT data, which covered almost the whole city area. The purpose of this research was to calculate the shear wave velocity of the top $30 \mathrm{~m} \mathrm{Vs}_{30}$ of the soil profile. In general, it is recommended that engineers consider all available data including site geology, available measured profiles, and site-specific geotechnical data. Shear wave velocity $\mathrm{Vs}_{30}$, predominant periods and estimated PGA maps are produced as the main results for seismic microzonation in Mandalay City. The kriging method can be used for the interpolation of subsurface information such as predominant period, shear wave velocity and PGA with the QGIS software. By combining the 2012, PSHA model Myanmar and the results of site magnification parameters, we proposed the distribution of the estimated peak ground acceleration of the urban Mandalay City, Myanmar. The PGA, average shearwave velocity $\mathrm{Vs}_{30}$ and predominant period maps are the basic needs for engineering purposes for every seismically active area or region. From this research, seismic microzonation 
was carried out by means of PGA at Mandalay City. Because of gradual growth of the population and the high-rise building, seismic microzonation analysis in absolutely needed to perform. These results are enormously required for Mandalay region for engineering purposes. The outputs of this research would be very applicable for both engineering purpose and to identify and mitigate the seismic risk for Mandalay City, Myanmar.

\section{Acknowledgements}

This research project is supported by Ministry of Education, Myanmar and AUN/SEED-Net, JICA. The acknowledgement is extended to Dr. Myo Thant in Monywa University for his empowerment and advices. Thanks are also dedicated to Dr. Tun Naing, Yangon Technological University for the help in undertaking the reference of Mandalay City maps.

\section{References}

[1] Noetling, F. 1900. The Miocene of Burma. Edited by Miller, J., GSA Memoir Deel VII, vol. 2., Amsterdam.

[2] Swe, W. 1981. “A Major Strike Slip Fault in Burma.” In Contributions to Burmese Geology, pp. 63-72.

[3] Thein, M., Tint, K., and Aung, A. K. 1991. "On the Lateral Displacement of the Sagaing Fault.” Georeports 1 (1): 23-34.

[4] Currey, J. R., Moore, D. G., Lawver, L. A., Emmel, F. J., Raitt, R. W., Henry, M., and Kiekhefer, R. 1979. "Tectonics of the Andaman Sea and Burma." Am. Assoc. Petr. Geol. Mem. 29: 189-98.

[5] Mitchell, A. H. G. 1981. "Phanerozoic Plate Boundaries in Mainland Southeast Asia, the Himalayas and Tibet.” Journal of Geological Society London 138: 109-22.

[6] Swe, W. N. W. 2008. "Seismicity and Major Active Faults of Myanmar." Journal of the Myanmar Geosciences Society 1 (1): 1-20.

[7] LeDain, A. Y., Tapponnier, P., and Molnar, P. 1984. "Active Faulting and Tectonics of Burma and Surrounding Regions.” Journal of Geophysical Research 89: 453-72.

[8] Maung, H. 1987. "Transcurrent Movements in the
Burma-Andaman Region.” Geology 15: 911-2.

[9] Watkinson.,and Tun, S T. 2017. "Segmentation of the Sagaing Fault.” Myanmar.

[10] Chibber, H. L. 1934. The Geology of Burma. London: Macmilland Com. \& Limited, p. 538.

[11] Thant, M., Mon, C. T., Tin, T. H., Oo, K. K. K., Aung, L. T., Kyi, S. S., Kawase, K. S. S., and Aung., D. W. 2013. "Development of Seismic Hazard Maps for Mandalay, Mandalay Region.” Presented at International Conference on Geological Engineering, Yogyakarta, Indonesia.

[12] U.S. Geological Survey. 2017. "Significant Earthquakes of the World 2017."

[13] Bernard R, W., Jason, T. D., and Thomas, S. 2012. Guidelines for Estimation of Shear Wave Velocity Profiles. Pacific Earthquake Engineering Research Center, PEER Report 2012/08.

[14] Kiyono, J., and Suzuki, M. 1996. "Conditional Simulation of Stochastic Waves by Using Kalman Filter and Kriging Techniques.” Presented at the 11th World Conference on Earthquake Engineering, Acapulco, Mexico.

[15] Noguchi, T., Horio, T., Kubo, M., Ono, Y., Kiyono, J., Ikeda, T., and Rusnardi, P. R. 2009. Estimation of Subsurface Structure in Padang, Indonesia by Using Microtremor Observation. Report on earthquake disaster prevention field, Tono Research Institute of Earthquake Science. (in Japanese)

[16] Thein, P. S., Pramumijoyo, S. S., Brotopuspito, K. S., Kiyono, J., Wilopo, W., Furukawa, A., Setianto, A., and Putra, R. R. 2015. "Estimation of S-Wave Velocity Structure for Sedimentary Layered Media Using Microtremor Array Measurements in Palu City, Indonesia.” In Proceedings of the 5th Sustainable Future for Human Security (Sustain 2014), Science Direct, Procedia Environmental Sciences 28: 595-605.

[17] Thein, M., and Swe, T. L. 2006. "Explanatory Account for Seismic Zone Map of Myanmar.” Myanmar Earthquake Committee, Myanmar Engineer Society.

[18] Thein, M., Myint, T., Tun, S. T., and Swe, T. L. 2009. "Earthquake and Tsunami Hazard in Myanmar.” Journal of Earthquake and Tsunami 3 (2): 43-57.

[19] Naing, T. 2017. The Seismic Zone Map of Mandalay, Myanmar. Technical Report.

[20] Thant, M., Khaing, S. N., Min, S., Aung, T., Tun, S. T., Kawase, H., Chan, C. H., and Wang, Y. 2012. New Probabilistic Seismic Hazard Models of Myanmar. Seismological Report. 